\title{
Transcriptional adaptation of pneumococci and human pharyngeal cells in the presence of a virus infection
}

\author{
Sheila Z Kimaro Mlacha ${ }^{1,2,6}$, Teresa C T Peret ${ }^{3}$, Nikhil Kumar ${ }^{2}$, Sandra Romero-Steiner ${ }^{4}$, Julie C Dunning Hotopp ${ }^{2}$, \\ Nadeeza Ishmael ${ }^{2}$, Valerie Grinblat-Huse ${ }^{2}$, David R Riley², Dean D Erdman ${ }^{3}$, George M Carlone ${ }^{4}$, \\ Jacquelyn Sampson ${ }^{4}$, J Anthony G Scott ${ }^{1,5}$ and Hervé Tettelin ${ }^{2^{*}}$
}

\begin{abstract}
Background: Viral upper respiratory tract infections are associated with increased colonization by Streptococcus pneumoniae but the mechanisms underlying this relationship are unclear. The objective of this study is to describe a comprehensive picture of the cellular interaction between the adhering bacteria and host cells in the presence or absence of a viral co-infection.

Results: Gene expression profiles of Detroit-562 pharyngeal cells, which were either mock-infected or infected with human respiratory syncytial virus (RSV) or human parainfluenza virus 3 (HPIV3), were analyzed using human microarrays. Transcription response of S. pneumoniae strain TIGR4 (serotype 4) in the presence of either mock- or viral-infected cells was analyzed by pneumococcal microarray. Significantly regulated genes were identified by both significance analysis of microarray (SAM) and $a \geq 2$-fold change ratio cut-off. The adherence of S. pneumoniae to human pharyngeal cells was significantly augmented in the presence of RSV or HPIV3 infection. Global gene expression profiling of the host cells during infection with RSV or HPIV3 revealed increased transcription of carcinoembryonic antigen-related cell adhesion molecules (CEACAM1), CD47, fibronectin, interferon-stimulated genes and many other host cell adhesion molecules. Pneumococci increased transcription of several genes involved in adhesive functions (psaA, pilus islet), choline uptake and incorporation (lic operon), as well as transport and binding.
\end{abstract}

Conclusions: We have identified a core transcriptome that represents the basic machinery required for adherence of pneumococci to D562 cells infected or not infected with a virus. These bacterial genes and cell adhesion molecules can potentially be used to control pneumococcal adherence occurring secondary to a viral infection.

Keywords: Streptococcus pneumoniae, RSV, HPIV3, Gene expression, Microarray, Adherence, Bacterial-viral co-infection

\section{Background}

Viruses play a pivotal role in modulating host cells, consequently mediating bacterial superinfection [1-8]. However, the mechanisms responsible for promoting bacterial superinfection are poorly understood. There are two potential explanations: (a) the virus changes the structure of the respiratory tract, paving the way for bacterial pathogens [1,9-12]; or (b) the virus alters the host's innate immune

\footnotetext{
* Correspondence: tettelin@som.umaryland.edu

${ }^{2}$ Department of Microbiology and Immunology, Institute for Genome Sciences, University of Maryland School of Medicine, Baltimore, MD, USA Full list of author information is available at the end of the article
}

response, making it more susceptible to bacterial infections [13-17].

Although several studies have demonstrated suppression of the host's immune response as a potential mechanism for bacterial superinfection, the degree of bacterial infection induced by prior viral infection is indistinguishable from that shown using experimental models without a complete immune system e.g. in vitro adhesion assays. This suggests separate or additional mechanisms of action that are independent of immune mechanisms. Studies of polymicrobial interactions have revealed that cellular receptors such as CD14, CD15, CD18, carcinoembryonic antigen-related cell adhesion molecule (CEACAM),

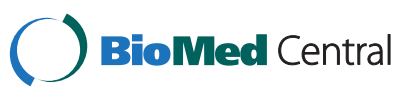


macrophage receptor (MARCO), platelet-activating factor (PAFR), fibronectin (FN) and fimbriae-associated receptors are likely to be involved in increased bacterial adherence after viral infection [9,11,14,18-21]. Given the diversity of host receptors, this list of adhesion molecules is unlikely to be exhaustive. Only a few studies have examined the local surface remodeling of human pharyngeal cells by viruses despite the fact that they are the portal of entry for both viruses and bacteria. The full range of adhesion molecules that can be up-regulated during a respiratory viral infection and facilitate bacterial attachment and entry is still unknown.

Some studies suggest that bacterial factors also play a part in this interaction, but whether or not bacteria modulate their surface structures to enhance adherence in the presence of viral infection remains controversial [19,22-24]. Several pneumococcal adhesins have been described [25-27] but their significance in virus-enhanced adherence has not been studied. PspA is the only pneumococcal virulence factor that has been shown to contribute to secondary pneumococcal infections after viral infection [22]. We sought to examine the genes expressed by Streptococcus pneumoniae when in contact with virus-infected cells in order to facilitate the design of vaccine and therapeutic targets to control bacterial adherence during polymicrobial infections. We used DNA microarrays to obtain a comprehensive view of: (a) the responses of human pharyngeal cells to infection with respiratory syncytial virus (RSV) and human parainfluenza virus type 3 (HPIV3) and (b) the effect that the viral infection has on both attachment and gene regulation of the pneumococcus.

\section{Methods}

\section{Bacterial and viral strains and cell lines}

TIGR4 [28] and G54 [29] pneumococcal strains, respiratory syncytial virus (RSV) strain ch 93-18b and human parainfluenza virus 3 (HPIV3) strain C243 were used in this study. The RSV strain was originally obtained from the University of Rochester Medical Center and the HPIV3 strain originated from the CDC respiratory repository. Pharyngeal human carcinoma epithelial cells (Detroit 562, CCL138) were obtained from ATCC (Rockville, MD, USA) and were grown and maintained as previously described [26].

\section{Viral infection scheme and adherence assay}

Tissue culture microtiter plates were seeded with $200 \mu \mathrm{l}$ of a $2 \times 10^{5} \mathrm{D} 562$ cells $/ \mathrm{ml}$ suspension per well and grown for $\sim 4 \mathrm{~d}$ to about $80 \%$ confluence $\left(9.6 \times 10^{4}\right.$ cells/well). Semi-confluent monolayers were washed twice with phosphate buffered saline (PBS) and inoculated with a $100 \mu \mathrm{l}$ volume of viral suspension. To infect monolayers with $\mathrm{RSV}$, the virus stock containing $6.5 \times 10^{6} \mathrm{TCID}_{50} / \mathrm{ml}$ was diluted to $10^{-1}$ to $10^{-3}$ with minimal essential medium with Eagle's salts (EMEM) (Gibco Laboratories, Grand Island, NY, USA), supplemented with penicillin $(50 \mu \mathrm{g} / \mathrm{ml})$, streptomycin $(50 \mu \mathrm{g} / \mathrm{ml})$ and $2 \%$ fetal bovine serum (FBS) (Hyclone, Logan, UT, USA). Each dilution of the virus was inoculated in triplicate. For HPIV3, the virus stock containing $8.3 \times 10^{7} \mathrm{TCID}_{50} / \mathrm{ml}$ was diluted to $10^{-3}$ to $10^{-6}$ with serum-free EMEM containing penicillin (100 $\mu \mathrm{g} / \mathrm{ml})$, streptomycin $(100 \mu \mathrm{g} / \mathrm{ml})$ and supplemented with crystallized porcine trypsin. Each virus dilution was inoculated into six wells. The negative control, which constituted of the same culture medium used for viral inoculation but without the virus, was seeded in another six wells. Plates were incubated at $37^{\circ} \mathrm{C}$ in a $5 \%$ $\mathrm{CO}_{2}$ incubator and, at $24 \mathrm{~h}$ intervals after inoculation (24-72 h for RSV and 24-120 h for HPIV3), were used for pneumococcal adherence experiments as previously described [26]. Briefly, monolayers were washed once with $125 \mu \mathrm{l} /$ well of EMEM without L-glutamine and supplemented with 7\% FBS (Atlas Biologicals, Fort Collins, CO). To the washed monolayer of each well, 80 $\mu \mathrm{l}$ of EMEM was added, followed by $20 \mu \mathrm{l} /$ well of bacterial suspension $\left(10^{3}\right.$ bacteria/well). The final D562 cell yield was $1.2 \times 10^{5}$ cells/well after 6 days of incubation resulting in an MOI of 0.01 . Plates were incubated for $2 \mathrm{~h}$ at $37^{\circ} \mathrm{C}$ in a $5 \% \mathrm{CO}_{2}$ incubator to allow for adherence then washed $5 \mathrm{X}$ with $\mathrm{PBS}$ with $0.2 \%$ bovine serum albumin (BSA) to remove non-adherent pneumococci. A $65 \mathrm{ml}$ volume of Todd-Hewitt broth supplemented with $0.5 \%$ yeast extract (THYE), 0.8\% agar, and 0.1\% 2,3,5-triphenyl tetrazolium chloride (TTC; Difco Laboratories), was added and the plates were incubated overnight at $37^{\circ} \mathrm{C}$ in a $5 \%$ $\mathrm{CO}_{2}$ incubator. The number of colonies of S. pneumoniae adhering to D562 cells was counted using an automated colony counter (AlphaImager; Alpha Innotech, CA). Adherence to both mock-infected cells (medium with no virus) and virus-infected cells was expressed as the mean ( \pm standard error of the mean, SEM) number of colony forming units (CFUs) in at least 3 replicate wells. Differences in adherence between virus- and mockinfected cells were tested by Student's $t$-test $(p<0.05)$. RSV or HPIV3 growth was detected and monitored by the use of an indirect immunofluorescence assay (Light Diagnostics Respiratory Viral Screen IFA, Millipore Corporation, Billerica, MA).

It is worth noting that although the adherence assays in this and in the accompanying manuscript by Kimaro Mlacha et al. were performed the same way, there was one difference in the treatment of mock-infected D562 cells (cells not infected with viruses) prior to the adherence assay. For this manuscript, the D562 cells were manipulated before reaching 100\% confluence. At day 4, cells were washed to allow for viral inoculation. This manipulation of the monolayer might have resulted in fewer D562 cells 
being present at day 6 compared than those in the accompanying manuscript, which were left intact for 6 days. Despite this difference, the mock-infected and virus-infected cells within the assay described in this manuscript were treated exactly the same way, making the comparison relevant within this experiment.

For microarray experiments, semi-confluent D562 cells grown in tissue culture flasks were either mock-infected or infected with stock virus at $6.5 \times 10^{5} \mathrm{TCID}_{50} / \mathrm{ml}$ for RSV and $8.3 \times 10^{3} \mathrm{TCID}_{50} / \mathrm{ml}$ for HPIV3, and incubated at $37^{\circ} \mathrm{C}$ on a shaker. After $1 \mathrm{~h}$ of adsorption, fresh medium was added into each flask and cultures were incubated at $37^{\circ} \mathrm{C}$ for $3 \mathrm{~d}$. The D562 cells were used for: (a) pneumococcal microarray experiments or (b) analysis of host-cell transcription profiles upon exposure to RSV or HPIV3. (a) Virus-infected and mock-infected cells were inoculated with $1 \mathrm{ml}$ of pneumococcal TIGR4 strain containing $10^{7}$ bacteria and incubated for $2 \mathrm{~h}$ at $37^{\circ} \mathrm{C}$ in a $5 \% \mathrm{CO}_{2}$ incubator. Non-adherent bacteria (contained in the spent cell culture medium) were removed and cells were washed $3 \mathrm{X}$ with PBS and then treated immediately with $10 \mathrm{ml}$ of RNAprotect (Qiagen, Valencia, CA, USA). Adherent bacteria were dissociated from host cells by lysis with $0.1 \%(\mathrm{w} / \mathrm{v})$ saponin in PBS followed by sonication using $5 \mathrm{~s}$ pulses for $1 \mathrm{~min}$. Bacteria were subsequently harvested by differential centrifugation. Control bacteria, which were not exposed to host cells, were suspended in EMEM medium and then prepared in parallel and treated identically to adherent bacteria. Pellets were stored at $-80^{\circ} \mathrm{C}$. (b) After inoculation of semiconfluent D562 cells with viruses for $3 \mathrm{~d}$, the viral suspension (or un-inoculated media for mock-infected controls) was removed from the monolayer and the cells were washed twice with PBS with $0.2 \%$ BSA. Subsets of the monolayers (both mock and virus-infected) were inoculated with $1 \mathrm{ml}$ of pneumococcal TIGR4 strain suspension containing $10^{7}$ bacteria, and the remaining monolayers were mock-infected with EMEM. All monolayers were incubated for $2 \mathrm{~h}$ at $37^{\circ} \mathrm{C}$ in a $5 \% \mathrm{CO}_{2}$ incubator then washed $2 \mathrm{X}$ with PBS with $0.2 \%$ BSA. D562 cells were detached by treatment with $0.025 \%$ trypsin-EDTA (Gibco Laboratories, Grand Island, NY, USA), and cell clumps were disrupted by gently pipetting up and down. The cells were collected by centrifugation at $800 \times g$ for $5 \mathrm{~min}$ and immediately placed into $5 \mathrm{vol}$ of RNAlater (Ambion, Austin, TX, USA) to minimize RNA degradation. Samples were stored at $4^{\circ} \mathrm{C}$ overnight to allow RNAlater solution to thoroughly penetrate the cells. The supernatant was then removed and the pellet was stored at $-80^{\circ} \mathrm{C}$ until further processing.

\section{RNA preparation}

Total RNA was isolated from: (a) RNA-stabilized bacteria adherent to either mock- or virus-infected D562 cells and bacteria growing freely in EMEM and (b) monolayers of D562 cells either mock-infected or infected with RSV or HPIV3. RNA was extracted using TRIzol (Invitrogen Life Technologies, Carlsbad, CA, USA) in a lysing matrix containing silica beads on a FastPrep Instrument (MP Biomedicals, Solon, OH, USA) according to the manufacturer's protocol. RNA was purified with the RNeasy Mini Kit (Qiagen, Valencia, CA, USA) and the quality was assessed using the prokaryote and eukaryote total RNA chips on the Agilent 2100 Bioanalyzer (Agilent Technologies, Santa Clara, CA, USA).

\section{Microarray experiments}

Bacterial microarray experiments were performed on version $6 \mathrm{~S}$. pneumoniae DNA microarrays distributed by the Pathogen Functional Genomics Resource Center (PFGRC, J. Craig Venter Institute, Rockville, MD, USA) and consisted of 70-mer oligonucleotides representing open reading frames (ORFs) from the genomes of three strains: TIGR4, G54 and R6, as well as 10 amplicons and 500 70-mer oligonucleotides from Arabidopsis thaliana, which served as negative controls. The experiments were performed as previously described [30]. For analysis of the human host cell response, microarrays with PCR amplicons of 41,000 cDNA clones were used (kindly provided by Norman Lee at George Washington University, Washington, DC, USA). Preparation of labeled cDNA target and hybridization experiments were done as previously described [30] with the exception that for the human host cell response, the starting amount of RNA used to synthesize cDNA was $5 \mu \mathrm{g}$. Total RNA was isolated from 3 independent cultures (biological replicates) of TIGR4 strain and D562 cells. Dye-swap experiments (technical replicates) were also performed on each biological replicate.

\section{Data normalization and analysis}

Data were analyzed using the TM4 microarray software suite [31]. Spot intensities were quantified using Spotfinder v3.1.1. Normalization was performed using the iterative log mean centering algorithm implemented in the MIDAS software (v2.19), and the fluorescence ratios were calculated from the normalized values. Data from the independent replicate experiments (only where $n \geq 15$ ) were averaged using locally developed Perl scripts and the resultant averages used for clustering algorithms to check for similar patterns in gene expression. Hierarchical clustering (HCL) using average linkage and Euclidean distance was also performed on the data to check for variability across replicate slides. To determine whether the observed ratio changes in expression of genes were both statistically and biologically significant, we applied the double filter of: (a) a statistical test, significance analysis of microarrays (SAM) and (b) a threshold ratio of 
relevant magnitude - a two-fold rise/fall in signal. For SAM analysis, a $\Delta$ value of 1.18 was used for TIGR4 in contact with mock-infected and $\Delta=2.158$ for TIGR4 in contact with viral-infected cells. This $\Delta$ cutoff corresponded to a false positive rate of $0 \%$. We also included into the final analysis all statistically significant genes that did not meet the threshold value but appeared to be co-regulated with one of our identified genes as part of an operon. For analysis of the human host cell response to viruses, a less stringent fold change cut-off of 1.5 was used since the overall gene expression changes were generally lower on the human microarrays.

\section{Validation of human microarray data by qRT-PCR}

Reverse transcription was carried out using the QuantiTect Reverse Transcription Kit (Qiagen, Valencia, CA, USA) in accordance with the manufacturer's instructions. Briefly, $1 \mu \mathrm{g}$ of total RNA was incubated in gDNA Wipeout Buffer (7X) and RNase-free water and incubated at $42^{\circ} \mathrm{C}$ for 2 min to remove contaminating genomic DNA. The cDNA was synthesized from the RNA using Quantiscript reverse transcriptase (RT), Quantiscript RT buffer (5X), and a primer mix at $42^{\circ} \mathrm{C}$ for $15 \mathrm{~min}$ and then at $95^{\circ} \mathrm{C}$ for 3 min to inactivate the Quantiscript RT. Dilutions of the cDNA $(0.25 \mu \mathrm{l}$ of the above mixture per $20 \mu$ l reaction) were used as template in a reaction containing $2 \mathrm{X}$ QuantiTect SYBR Green mix (Qiagen, Valencia, CA, USA), RNase-free water and gene-specific primers (Additional file 1: Table S1). The qRT-PCR assays were conducted using an ABI 7900HT instrument (Applied Biosystems, Carlsbad, CA, USA). The reactions were denatured at $95^{\circ} \mathrm{C}$ for $15 \mathrm{~min}$ followed by amplification with 45 cycles of $94^{\circ} \mathrm{C}$ for $15 \mathrm{~s}, 55^{\circ} \mathrm{C}$ for $30 \mathrm{~s}$ and $72^{\circ} \mathrm{C}$ for $30 \mathrm{~s}$. Data was analyzed using a comparative cycle threshold $(\Delta \mathrm{Ct})$ method [32]. The $\Delta \mathrm{Ct}$ was normalized to a gene (NG_007992 actin gene) that did not exhibit any significant change in expression as identified by the microarray experiments. Each sample was tested in triplicate.

A similar procedure was used for qRT-PCR validation of pneumococcal microarray data. The primers used are listed in Additional file 1: Table S2.

\section{Results}

\section{Effect of RSV and HPIV3 infection on the adherence of S. pneumoniae to human pharyngeal cells}

D562 cells were permissive to infection with RSV and HPIV3, with discrete cytopathic effect (CPE) after $72 \mathrm{~h}$ but without much detachment of the monolayers hence allowing for pneumococcal adherence. We then investigated whether pneumococci adhered in greater numbers to virus-infected D562 cells than to mock-infected cells. The optimal incubation period of virus-infected cells required for maximum bacterial adherence was determined to be $72 \mathrm{~h}$ in a preliminary time-course experiment (data not shown). The adherence of pneumococcal strains TIGR4 and G54 to D562 cells increased significantly with prior viral infection $(p<0.05)$ (Figure 1$)$. The degree of enhanced attachment ranged from 1.3- to 2-fold and was dependent on the dose of initial viral infection. Maximal adherence due to RSV infection was obtained at a viral titer of $6.5 \times 10^{5} \mathrm{TCID}_{50} / \mathrm{ml}$, and maximal adherence to HPIV3 was obtained at a viral titer of $8.3 \times 10^{3} \mathrm{TCID}_{50} / \mathrm{ml}$. This influence of viral dose on bacterial adherence was similar for both pneumococcal strains, although the strains varied markedly in their baseline adherence capacity without viral infection (Figure 1).

Gene expression patterns of S. pneumoniae in contact with either virus- or mock-infected human pharyngeal cells

To limit the number of variables being compared for the gene expression analysis, we restricted the experiments to one strain of pneumococcus, TIGR4, and one respiratory virus - HPIV3. RNA was isolated from TIGR4 in contact with HPIV3- or mock-infected D562 cells.

Compared to controls (pneumococci in cell culture medium), the gene regulation ratios for pneumococci in contact with virus- or mock-infected pharyngeal cells varied from 0.1 to 14.4 . Among the 77 genes that were up-regulated, 51 were regulated in both virus-infected and mock-infected conditions (Additional file 1: Table S3). These included genes involved in adhesive functions (psaA, pilus islet), choline uptake and incorporation (lic operon), transport and binding (SP_1855-SP_1857) and fatty acid metabolism (SP_0421-SP_0427). The most highly represented genes were those coding for hypothetical proteins (25\%), some of which are putative membrane proteins. Of the 98 down-regulated pneumococcal genes, 62 were down-regulated in both virusinfected and mock-infected conditions and these included choline transporters (proWX, proV) and purine biosynthesis genes (pur operon) (Additional file 1: Table S3). Among these 51 up-regulated and 62 down-regulated genes, the degree of regulation was remarkably consistent in the two adherence conditions (Additional file 1: Figure S1). These genes underpin the common set of cell functions that are induced by exposure to pharyngeal cells - regardless of whether those cells are viral-infected.

Eight pneumococcal genes appeared in the list of genes that were up-regulated after contact with HPIV3-infected cells but were absent in the list of genes up-regulated after contact with mock-infected cells. These were: $\operatorname{gln} Q$, a fibronectin-binding/glutamine transport gene, SP_0204SP_0206, ribonucleotide reductase genes, SP_1428 and SP_2005, genes encoding hypothetical proteins, and SP_1765-SP_1767, glycosyl transferase genes. Upon further examination, we found that these genes were absent from the list of genes up-regulated by TIGR4 in contact with mock-infected cells because they did 

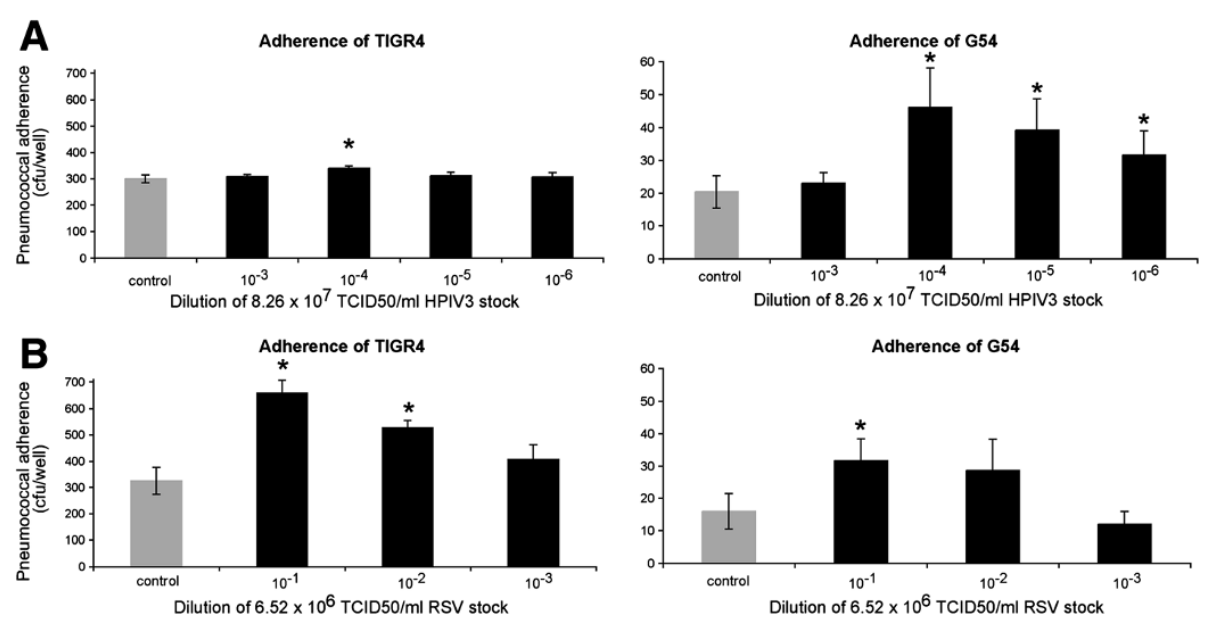

Figure 1 Binding of S. pneumoniae TIGR4 and G54 to D562 cells infected with HPIV3 (A) or RSV (B). The number of bacteria adhering to mock-infected cells (gray) and to viral-infected cells (black) is shown. The number of bacteria is calculated as the mean ( \pm SEM) number of colony forming units observed in at least 3 replicate wells. Adhesion of pneumococci to viral-infected cells vs. mock-infected at varying viral doses is noted with a star $(p<0.05$, Student's test). Since the primary comparison in this figure is between mock-infected and virus-infected cells, the Y-axis scales for the two bacterial strains are different.

not meet our criteria for inclusion in the analysis (see Methods). We used qRT-PCR to verify the expression levels of these genes in both conditions, adherence to HPIV3-infected and mock-infected cells. The 8 genes had comparable $\mathrm{Ct}$ values between the two conditions. Eighteen genes, all encoding hypothetical proteins, were up-regulated by TIGR4 in contact with mock-infected cells only. It is likely that the expression of these 18 genes is inhibited by the viral infection.

\section{Effect of HPIV3 and RSV on the expression of human cell adhesion molecules}

Given the very large number of human genes and the particular hypothesis under test in this study, we focused our analysis on genes encoding cell adhesion molecules. HPIV3 infection induced the up-regulation of 55 human genes (Table 1A). Four of these were also up-regulated in RSV-infected cells (Table 1 panels A and B, CD47, AADACL1, ZC3HAV1 and cIAP2, an apoptosis inhibitor). Other genes that were up-regulated by HPIV3-infected cells included interferon stimulated genes (ISGs), plasminogen activator urokinase (PLAU), collagen type XVII alpha 1 , claudin 1 , laminin alpha 3 , matrix metallopeptidase 14, and molecules of the carcinoembryonic antigen-related cell adhesion molecules (CEACAM1). Infection with RSV induced the up-regulation of 20 genes, including proteins of the zinc finger family (ZNF23, ZNF318), protocadherin beta 19 , Rho family GTPase 1 , fibronectin type III domain containing protein, and caspase 10.
Since the results above suggested that the enhanced expression of various adhesion molecules following HPIV3 and RSV infection may increase the level of adherence of pneumococci, we sought to describe the transcription profiles of cell adhesion molecules exposed to the TIGR4 strain and compared them to the virus-induced transcription profiles. We found that genes that were regulated in the presence of HPIV3 and RSV were not significantly regulated in TIGR4; rather, infection with TIGR4 alone resulted in the up-regulation of a unique set of genes (Table 1C) which included selenium-binding protein 1 (SELENBP1), granulocyte colony stimulating factor receptor (CSF3R), and ADAM metallopeptidases. We also analyzed the transcription of host cells exposed to concurrent stimulation by both viral and bacterial pathogens and found that infection of D562 cells with HPIV3 or RSV followed by TIGR4 induced a similar response to that of infection with HPIV3 or RSV only (Table 1 panels $\mathrm{A}, \mathrm{B}$ and $\mathrm{C})$.

\section{Confirmation of microarray results by qRT-PCR}

A subset of differentially expressed genes from the human microarray experiments was selected and qRT-PCR analysis was undertaken to confirm the relative levels of gene expression. The experiments were performed on the same RNA samples used in microarray experiments. The correlation coefficient (R) between qRT-PCR and microarray results for pneumococcal transcription in contact with either virus-infected or mock-infected epithelial cells was 
Table 1 Differential expression of cell adhesion molecules

A. Genes up-regulated by infection with HPIV3

GB\# Gene name

AA406020 ISG15 ubiquitin-like modifier

AA456886 Myxovirus (influenza virus) resistance 1, interferon-inducible protein p78

AA286908 Myxovirus (influenza virus) resistance 2

T95113 Radical S-adenosyl methionine domain containing 2

AA126958 DEAD (Asp-Glu-Ala-Asp) box polypeptide 58

AA419251 Interferon induced transmembrane protein 1 (9-27)

AA421603 SAM domain and HD domain 1

Al245550 Phospholipid scramblase 1

AA995904 TCF3 (E2A) fusion partner

AA827287 Interferon-induced protein 35

H54629 Tumor necrosis factor (ligand) superfamily, member 10

AA862371 Interferon induced transmembrane protein 2 (1-8D)

AA877255 Interferon regulatory factor 7

R07870 Baculoviral IAP repeat-containing 3; inhibitor of apoptosis protein

Al038270 Eukaryotic translation initiation factor 2-alpha kinase 2

AA479795 Interferon stimulated exonuclease gene 20kda

N67034 Interferon-induced protein 44-like

\section{AA418724 Zinc finger CCCH-type, antiviral 1}

N75384 Peroxisome proliferator-activated receptor gamma, coactivator 1 beta

W37864 Phosphatase and tensin homolog

H17861 Ring finger protein 213

AA983252 Signal transducer and activator of transcription 2, 113kda

R70479 Tumor necrosis factor, alpha-induced protein 3

AA128561 Collagen, type XVII, alpha 1

Al016022 NLR family, CARD domain containing 5

N70463 B-cell translocation gene 1, anti-proliferative

H61758 ELK4, ETS-domain protein (SRF accessory protein 1)

R33456 Desmoplakin

\begin{tabular}{|c|c|c|}
\hline $\begin{array}{l}\text { Gene } \\
\text { symbol }\end{array}$ & $\begin{array}{l}\text { HPIV3-infected/ } \\
\text { mock-infected }\end{array}$ & $\begin{array}{l}\text { RSV-infected/ } \\
\text { mock-infected }\end{array}$ \\
\hline ISG15 & 23.80 & 1.10 \\
\hline MX1 & 23.68 & 1.11 \\
\hline$M \times 2$ & 13.84 & 1.06 \\
\hline RSAD2 & 11.72 & 0.90 \\
\hline DDX58 & 11.55 & 1.16 \\
\hline IFITM1 & 7.32 & 0.96 \\
\hline SAMHD1 & 5.67 & 0.96 \\
\hline PLSCR1 & 5.00 & 0.91 \\
\hline TFPT & 4.05 & 1.35 \\
\hline IFI35 & 3.85 & 1.10 \\
\hline TNFSF10 & 3.64 & NA \\
\hline IFITM2 & 3.37 & 0.85 \\
\hline IRF7 & 3.25 & $x$ \\
\hline- & 3.09 & 2.09 \\
\hline EIF2AK2 & 2.91 & 1.11 \\
\hline ISG20 & 2.91 & NA \\
\hline$|F| 44 L$ & 2.87 & 1.01 \\
\hline ZC3HAV1 & 2.82 & 1.53 \\
\hline PPARGC1B & 2.45 & 0.78 \\
\hline PTEN & 2.43 & 0.90 \\
\hline RNF213 & 2.26 & 1.05 \\
\hline STAT2 & 2.23 & $x$ \\
\hline TNFAIP3 & 2.17 & 0.75 \\
\hline COL17A1 & 1.95 & 1.11 \\
\hline NLRC5 & 1.93 & $x$ \\
\hline BTG1 & 1.90 & 1.43 \\
\hline ELK4 & 1.86 & 0.80 \\
\hline DSP & 1.82 & 1.03 \\
\hline
\end{tabular}

Fold change

TIGR4-infected/ HPIV3-TIGR4-infected/ RSV-TIGR4-infected/ mock-infected mock-infected mock-infected

$\begin{array}{lll}1.05 & 24.76 & 1.15\end{array}$

$\begin{array}{lll}1.04 & 16.12 & 1.12\end{array}$

1.05

1.11

0.88

0.99

0.89

0.95

1.05

0.95

1.18

0.92

1.06

1.20

0.99

1.10

1.05

1.31

0.94

0.93

1.03

1.12

1.03

1.99

$x$

1.13

0.87

$1.03 \quad 0.88$

12.35 
Table 1 Differential expression of cell adhesion molecules (Continued)

\begin{tabular}{|c|c|c|c|c|c|c|c|}
\hline Al085559 & Arylacetamide deacetylase-like 1 & AADACL1 & 1.80 & 1.64 & $\mathrm{x}$ & 1.69 & 1.79 \\
\hline AA609992 & Dehydrogenase/reductase (SDR family) member 9 & DHRS9 & 1.78 & 1.45 & 0.95 & 1.09 & 1.50 \\
\hline AA136060 & Polycomb group ring finger 5 & PCGF5 & 1.74 & 0.99 & 0.96 & 1.21 & 0.82 \\
\hline Al364513 & Scavenger receptor class B, member 2 & SCARB2 & 1.72 & 1.06 & NA & NA & 0.97 \\
\hline AA491191 & Interferon, gamma-inducible protein 16 & IFI16 & 1.72 & 1.38 & 0.94 & 0.97 & 1.99 \\
\hline AA451844 & $\begin{array}{l}\text { Microtubule associated monoxygenase, calponin and LIM } \\
\text { domain containing } 2\end{array}$ & MICAL2 & 1.70 & 0.91 & 0.91 & $x$ & 0.79 \\
\hline R92801 & CD47 molecule & CD47 & 1.68 & 1.57 & 1.01 & 1.16 & 1.64 \\
\hline R93911 & Glycogen synthase kinase 3 beta & GSK3B & 1.68 & 1.29 & NA & NA & 1.32 \\
\hline AA776304 & Pleckstrin 2 & PLEK2 & 1.67 & 0.97 & NA & 1.81 & 1.08 \\
\hline AA490894 & Endoplasmic reticulum aminopeptidase 1 & ERAP1 & 1.67 & 1.19 & 0.87 & $x$ & 1.25 \\
\hline AA777854 & Ring finger protein 12 & RNF12 & 1.67 & 0.85 & 0.99 & NA & 0.92 \\
\hline AA040699 & ELK3, ETS-domain protein (SRF accessory protein 2) & ELK3 & 1.65 & 0.99 & 0.91 & $x$ & 0.86 \\
\hline H95362 & Claudin 1 & CLDN1 & 1.64 & 0.83 & NA & 1.26 & 1.20 \\
\hline AA411757 & $\begin{array}{l}\text { Carcinoembryonic antigen-related cell adhesion molecule } 1 \\
\text { (biliary glycoprotein) }\end{array}$ & CEACAM1 & 1.63 & $x$ & NA & 1.41 & 0.51 \\
\hline AA284668 & Plasminogen activator, urokinase & PLAU & 1.63 & 1.15 & 1.27 & $x$ & 1.25 \\
\hline AA135422 & CCR4-NOT transcription complex, subunit 1 & CNOT1 & 1.63 & 0.99 & 0.89 & 1.04 & 1.05 \\
\hline Al049712 & Epidermal growth factor receptor & EGFR & 1.62 & 1.00 & 0.91 & 1.13 & 0.96 \\
\hline N70848 & Ring finger protein 141 & RNF141 & 1.58 & 1.11 & 0.94 & 1.08 & 0.90 \\
\hline AA005112 & LIM domain 7 & LMO7 & 1.58 & 0.89 & 0.83 & 0.81 & 0.77 \\
\hline AA488674 & Myeloid cell leukemia sequence 1 (BCL2-related) & MCL1 & 1.58 & 0.96 & $x$ & $x$ & 0.84 \\
\hline AA018412 & Coiled-coil domain containing 93 & CCDC93 & 1.57 & 0.92 & 1.11 & 1.03 & 0.85 \\
\hline AA478738 & Catenin, beta interacting protein 1 & CTNNBIP1 & 1.55 & 0.97 & 0.88 & $x$ & 1.03 \\
\hline Al652954 & $\begin{array}{l}\text { Transglutaminase } 1 \text { (K polypeptide epidermal type I, protein- } \\
\text { glutamine-gamma-glutamyltransferase) }\end{array}$ & TGM1 & 1.54 & 0.67 & 0.86 & 1.05 & 0.56 \\
\hline N59721 & $\begin{array}{l}\text { Serpin peptidase inhibitor, clade E (nexin, plasminogen } \\
\text { activator inhibitor type 1), member } 2\end{array}$ & SERPINE2 & 1.54 & 0.69 & 0.88 & $x$ & 0.93 \\
\hline AA001432 & Laminin, alpha 3 & LAMA3 & 1.53 & 1.23 & 0.86 & 0.94 & 1.21 \\
\hline AA706099 & NEDD4 binding protein 1 & N4BP1 & 1.52 & 1.08 & 1.01 & 1.19 & 0.98 \\
\hline N33214 & Matrix metallopeptidase 14 (membrane-inserted) & MMP14 & 1.52 & 0.84 & 0.79 & 1.26 & 0.91 \\
\hline \multicolumn{8}{|c|}{ B. Genes up-regulated by infection with RSV } \\
\hline AA406373 & Transporter 2, ATP-binding cassette, sub-family B (MDR/TAP) & TAP2 & 1.46 & 2.28 & 1.10 & 1.18 & 1.27 \\
\hline AA620877 & Protein tyrosine phosphatase, receptor type, $\mathrm{M}$ & PTPRM & $x$ & 2.11 & 1.10 & 1.18 & 1.27 \\
\hline
\end{tabular}


Table 1 Differential expression of cell adhesion molecules (Continued)

\begin{tabular}{|c|c|c|c|c|c|c|c|}
\hline R07870 & $\begin{array}{l}\text { Baculoviral IAP repeat-containing 3; inhibitor of apoptosis } \\
\text { protein }\end{array}$ & - & 3.09 & 2.09 & 1.20 & 1.79 & 1.60 \\
\hline AA701353 & Hypothetical protein LOC92270 & LOC92270 & 0.79 & 2.07 & 0.90 & 1.34 & 2.45 \\
\hline AA001983 & Hypothetical LOC92482 & LOC92482 & 0.83 & 1.74 & 1.08 & NA & $x$ \\
\hline Al014782 & Trinucleotide repeat containing $6 \mathrm{~B}$ & TNRC6B & 1.22 & 1.99 & 1.08 & 0.86 & 1.88 \\
\hline H80712 & Caspase 10 , apoptosis-related cysteine peptidase & CASP10 & $x$ & 1.73 & 0.79 & $x$ & 1.84 \\
\hline H23077 & Rho family GTPase 1 & RND1 & $x$ & 1.71 & $x$ & NA & 1.75 \\
\hline AA903644 & Protocadherin beta 19 pseudogene & PCDHB19P & 0.84 & 1.65 & $x$ & $x$ & 1.67 \\
\hline A1085559 & Arylacetamide deacetylase-like 1 & AADACL1 & 1.80 & 1.64 & NA & 1.69 & 1.79 \\
\hline H01197 & $\begin{array}{l}\text { Pleckstrin homology domain containing, family F (with FYVE } \\
\text { domain) member } 2\end{array}$ & PLEKHF2 & 0.96 & 1.63 & 0.87 & 0.87 & 1.35 \\
\hline R36431 & Fibronectin type III domain containing $3 \mathrm{~A}$ & FNDC3A & 1.37 & 1.62 & 0.92 & 1.03 & 1.41 \\
\hline AA047413 & Zinc finger protein 23 (KOX 16) & ZNF23 & NA & 1.60 & 1.18 & $x$ & 1.20 \\
\hline AA903552 & Lysozyme-like 1, lysozyme-like 2 & $\begin{array}{l}\text { LYZL1, } \\
\text { LYZL2 }\end{array}$ & $x$ & 1.58 & NA & NA & 1.79 \\
\hline AA485438 & Ring finger protein 187 & RNF187 & 0.84 & 1.58 & 1.02 & 0.86 & 1.18 \\
\hline R92801 & CD47 molecule & CD47 & 1.68 & 1.57 & 1.01 & 1.16 & 1.64 \\
\hline Al168153 & $\begin{array}{l}\text { Pleckstrin homology domain containing, family A } \\
\text { (phosphoinositide binding specific) member } 8\end{array}$ & PLEKHA8 & $x$ & 1.57 & $x$ & $x$ & 1.41 \\
\hline AA878257 & Colony stimulating factor 1 & CSF1 & $x$ & 1.57 & NA & NA & 1.13 \\
\hline AA418724 & Zinc finger $\mathrm{CCCH}$-type, antiviral 1 & ZC3HAV1 & 2.82 & 1.53 & 1.31 & 1.77 & 1.49 \\
\hline Al004484 & Zinc finger protein 318 & ZNF318 & $x$ & 1.52 & 1.29 & NA & 1.62 \\
\hline \multicolumn{8}{|c|}{ C. Genes up-regulated by infection with TIGR4 } \\
\hline T65736 & Selenium-binding protein & SELENBP1 & 3.98 & 0.65 & 1.35 & 1.12 & NA \\
\hline Al093729 & ADAM metallopeptidase with thrombospondin type 1 motif, 2 & ADAMTS2 & 3.87 & 1.61 & 1.59 & 0.59 & NA \\
\hline AA443000 & Granulocyte colony stimulating factor receptor & CSF3R & 2.75 & 1.43 & 0.89 & 1.10 & 0.93 \\
\hline AA460304 & Human ribosomal DNA complete repeating unit & CRISPLD2 & 2.58 & NA & 1.27 & NA & 0.75 \\
\hline Al003033 & Neural cell adhesion molecule 2 & NCAM2 & 2.56 & 1.50 & 1.43 & 1.36 & 0.97 \\
\hline AA904923 & HNF1 homeobox B & HNF1B & 2.34 & 0.65 & 1.40 & NA & 1.30 \\
\hline AA521362 & $\begin{array}{l}\text { CR2/CD21/C3d/Epstein-Barr virus receptor complement } \\
\text { component receptor } 2\end{array}$ & CR2 & 2.33 & NA & 1.15 & NA & 0.99 \\
\hline T98262 & General transcription factor IIIC, polypeptide 3 & GTF3C3 & 2.33 & 0.96 & 1.50 & NA & 0.72 \\
\hline AA904604 & RIKEN & LOC143678 & 2.21 & 1.11 & 0.80 & 1.46 & 0.95 \\
\hline Al188215 & Neuregulin 1 & NRG1 & 2.21 & NA & 0.91 & NA & 0.80 \\
\hline
\end{tabular}


Table 1 Differential expression of cell adhesion molecules (Continued)

\begin{tabular}{|c|c|c|c|c|c|c|c|}
\hline W60968 & $\begin{array}{l}\text { Myelin protein zero-like protein2; Epithelial V-like antigen } 1 \\
\text { precursor }\end{array}$ & MPZL2 & 2.19 & NA & 2.47 & NA & 0.36 \\
\hline R88767 & Protocadherin 10; protocadherin 20 precursor & $\mathrm{PCDH} 20$ & 2.13 & 0.72 & 1.34 & NA & 0.81 \\
\hline R01281 & Src kinase-associated phosphoprotein1; SKAP55 protein & SKAP55 & 1.94 & NA & 1.22 & NA & 1.17 \\
\hline AA150694 & LY6/PLAUR domain containing 6 & LYPD6 & 1.85 & NA & 1.26 & NA & 1.08 \\
\hline AA707615 & Chromosome 9 open reading frame 116 & C9orf116 & 1.83 & 0.73 & 1.05 & NA & 0.87 \\
\hline H57180 & $\begin{array}{l}\text { Phospholipase C-like phospholipase C, gamma } 2 \\
\text { (phosphatidylinositol-specific) }\end{array}$ & PLCG2 & 1.82 & NA & 1.23 & NA & 1.09 \\
\hline AA883775 & Metallaproteinase-disintegrin & ADAM30 & 1.80 & 0.32 & 1.19 & NA & 2.26 \\
\hline Al361560 & Homeo box C9 & $\mathrm{HOXC9}$ & 1.76 & 0.59 & 0.91 & 0.89 & 0.93 \\
\hline Al380234 & Clqr(p) complement component C1q receptor & CD93 & 1.76 & 0.55 & NA & 0.56 & NA \\
\hline R86733 & Zinc finger protein & ZNF397 & 1.74 & NA & 1.59 & NA & 1.10 \\
\hline R08109 & Alu subfamily J sequence contamination warning entry & ZNF398 & 1.70 & 1.02 & 0.96 & 0.81 & 1.05 \\
\hline AA176413 & F-box protein Fbx20 & $\mathrm{FBX} 20$ & 1.70 & 0.36 & 1.08 & NA & 1.09 \\
\hline H90292 & Procollagen type $V$ alpha 2 & SERPINA1 & 1.70 & 1.77 & 0.94 & 1.47 & 0.76 \\
\hline AA680249 & Bactericidal/permeability-increasing protein & $\mathrm{BPI}$ & 1.69 & 1.20 & 2.06 & 1.24 & NA \\
\hline R43755 & Intraflagellar transport protein 57 homolog & ESRRBL1 & 1.68 & 1.35 & 1.28 & 0.97 & 1.05 \\
\hline AA620742 & Xenotropic and polytropic retrovirus receptor & XPR1 & 1.67 & 1.37 & 0.87 & 0.82 & 1.00 \\
\hline AA137073 & Integrin, beta-like 1 (with EGF-like repeat domains) & ITGBL1 & 1.66 & 0.81 & 1.03 & 0.74 & 0.99 \\
\hline T70368 & Integrin, beta 5 & ITGB5 & 1.66 & 1.03 & 1.09 & 1.64 & 1.01 \\
\hline R76099 & Toll-like receptor 3 & TLR3 & 1.62 & 0.58 & 0.83 & NA & 0.85 \\
\hline H52352 & Complement factor properdin & CFP & 1.62 & NA & 1.54 & NA & 0.54 \\
\hline R98903 & Scavenger receptor class B, member 1 & SCARB1 & 1.59 & NA & 1.01 & NA & 0.73 \\
\hline AA150507 & Interleukin 1, beta & IL1B & 1.59 & 1.99 & 1.81 & 1.17 & 0.56 \\
\hline T98612 & Alpha-1 type III collagen & COL3A1 & 1.57 & 1.74 & 0.83 & NA & 1.06 \\
\hline T52330 & Interleukin 6 receptor & IL6R & 1.57 & 1.36 & 1.06 & 1.07 & 1.17 \\
\hline AA010600 & Nuclear RNA export factor 3 & NXF3 & 1.56 & 1.58 & 1.23 & 0.99 & 1.00 \\
\hline AA176249 & Transforming growth factor, beta 2 & TGFB2 & 1.56 & 0.64 & 0.87 & NA & 1.18 \\
\hline R10099 & Stabilin-2 & STAB2 & 1.56 & 0.98 & 1.10 & 1.18 & 1.21 \\
\hline N32241 & Zinc finger protein 160 & ZNF160 & 1.55 & NA & 1.10 & NA & 1.06 \\
\hline W94121 & Tumor necrosis factor receptor superfamily, member 19 & TNFRSF19 & 1.55 & 1.17 & 1.06 & 0.53 & 0.92 \\
\hline H93115 & Ras association (ralgds/AF-6) and pleckstrin homology domains 1 & RAPH1 & 1.54 & 1.56 & 0.72 & 0.80 & NA \\
\hline AA455067 & Non-Ab component of amyloid peptide precursor & SNCA & 1.54 & NA & 1.14 & NA & 0.93 \\
\hline R68721 & Apo-2 ligand, TNF-related apoptosis inducing ligand TRAIL & TNFSF10 & 1.54 & NA & 0.83 & NA & 1.24 \\
\hline
\end{tabular}


Table 1 Differential expression of cell adhesion molecules (Continued)

AA456622 Wiskott-Aldrich syndrome protein interacting protein WIPFI

H74265 Protein tyrosine phosphatase, receptor type, C PTPRC

T68892 Secreted apoptosis related protein 2

PTPRC 1.53

1.54

NA

1.16

NA

AA780815 Alpha-2 type VIII collagen

SFRP1

1.52

NA

1.15

NA

1.20

Genes listed are up-regulated by infection with HPIV3 (A), RSV (B), and/or TIGR4 (C.

$\mathrm{X}$ indicates genes that did not meet the criteria established for microarray analysis (see Methods); NA indicates data points that had no single value. 
0.92 and 0.84 , respectively. On the host side, the correlation coefficient between the two conditions in HPIV-3 infected cells and RSV-infected cells were 0.87 and 0.65 , respectively (Additional file 1: Figure S2).

\section{Discussion}

Binding of pneumococci to virus-infected cells

In the present study, we have used a well-established model of adherence to demonstrate that infection of human pharyngeal cells with paramyxoviruses RSV or HPIV3 enhanced the adherence of S. pneumoniae strains TIGR4 and G54. While this finding is consistent with the results of other in vitro studies [21,33-35], this is the first report of RSV and HPIV3 increasing the in vitro adherence of $S$. pneumoniae to human pharyngeal cells (Detroit 562). The enhanced adherence of bacteria to virus-infected cells was consistent across both viruses and pneumococcal strains/serotypes evaluated. HPIV3 and RSV were used in this study as they are among the viruses most commonly predisposing to secondary bacterial infections [36,37]. The results also show that both the neuraminidase (NA)-positive (HPIV3) and NAnegative (RSV) viruses enhanced binding of pneumococci to pharyngeal cells. Viral neuraminidase cleaves terminal sialic acid on eukaryotic cells, unmasking receptors that facilitate pneumococcal adherence [38]. This suggests that NA-enhanced bacterial adherence is not the only mechanism for increased bacterial adherence following viral infection.

\section{Mechanism of viral/bacterial synergy: a bacterial standpoint}

We wanted to determine whether: (i) the pneumococcus is capable of detecting and responding to the host cell changes by expressing additional factors to complement newly expressed host cell receptors on the surface of viral-infected cells, or (ii) S. pneumoniae simply expresses the same baseline set of genes in response to contact with host cell regardless of the status of viral infection. In the latter case, the advantage of viral infection to pneumococcal adherence would be determined entirely by the viral effect on human cells. Our results demonstrate that there is a common set of pneumococcal genes that participate in the induction of adherence regardless of the presence of a virus. We believe that this study is the first to analyze the reciprocal response of S. pneumoniae to viral infection at a global transcriptome level.

As enhanced adherence was observed with both pneumococcal strains and with both viruses, we focused the pneumococcal microarray experiments on one strain-virus combination. We selected TIGR4 because it exhibited greater adherence to epithelial cells than G54, and we selected HPIV3 because it expresses NA. Our observation that multiple pneumococcal adhesins are regulated upon the binding of the bacterium to both mock- and virus-infected cells suggests that there is a common set of genes whose protein products represent good targets for designing interventions to prevent pneumococcal infection in the nasopharynx.

The up-regulated operon SP_0204-SP_0206 encodes a ribonucleoside triphosphate reductase $(n r d D)$ and its activating protein $(n r d G)$. This operon is active during anaerobic conditions $[39,40]$ and in many bacterial species, the operon is up-regulated to enable bacteria to survive during oxidative stress [39]. The gene $n r d G$ has been shown to be up-regulated in $S$. pneumoniae during infection of blood and meninges [41]. Human cells infected with viruses generate a large amount of inflammatory products and therefore up-regulation of this operon in the pneumococcus suggests the existence of oxygen tension. This is a plausible explanation of how the pneumococcus is able to resist this stressful environment and in the end confer the phenotype of enhanced adherence. McCullers and colleagues have proposed that fibrin and fibrinogen, deposited during the regenerative process following viral infection, may provide additional attachment sites for bacteria [2]. It was therefore interesting to observe that $g \ln Q$ (SP_1242), a gene previously shown to be required for adherence to fibronectin by group B Streptococcus [42] was significantly up-regulated in TIGR4 in contact with virus-infected cells. It is possible that it might have a specific adhesive function in S. pneumoniae on contact with virus-infected epithelial cells.

\section{Mechanism of viral/bacterial synergy: a host standpoint}

We hypothesized that viral infection can enhance bacterial adhesion by increasing the expression of host cell receptors. Our study supported this contention by showing that a variety of epithelial cell receptors (CEACAM1, CD47, interferon-stimulated genes, among others) were upregulated in response to HPIV3 and RSV infection. Other studies examining this question have either focused exclusively on the expression of a small number of cell adhesion receptors, or have studied non-human epithelial cells. CEACAM1 and CD47 have previously been identified in the host cell response to viral infection [21] and we have confirmed this observation with regard to HPIV3. CEACAM1 binds meningococcal and gonococcal opacityassociated (Opa) proteins and mediates internalization of the bacteria into several cell types in vitro [43]. It also binds to Haemophilus influenzae and Moraxella catarrhalis, which share their ecological niche with $S$. pneumoniae. Though the CEACAM-binding adhesins in S. pneumoniae are unknown, if they exist, the fact that CEACAM1 is one of a small number of genes up-regulated after viral infection suggests that this may be an area for future study. CD47, a gene encoding an integrin-associated protein, was up-regulated in response to infection by both 
HPIV3 and RSV in our study. Expression of CD47 has previously been shown to render mice susceptible to E. coli $\mathrm{K} 1$ meningitis [44].

Interestingly, the gene encoding a fibronectin type III domain-containing protein was up-regulated by the host in response to both viruses (significantly in RSV and moderately in HPIV3). In our pneumococcal gene expression studies, a fibronectin-binding gene, $g \ln Q$ was highly up-regulated in TIGR4 in contact with virusinfected cells. The symmetry of these observations suggests that virus-induced up-regulation of fibronectin type III induced a reciprocal response in S. pneumoniae in the form of up-regulation of a ligand to match the newly up-regulated host receptor. This is a specific hypothesis worth pursuing in future functional experiments.

Other genes that were significantly up-regulated in our study include several interferon-stimulated genes (ISGs) and the urokinase plasminogen activator (PLAU), which mediates a response to the inflammation induced by the virus. Induction of ISGs and NOD-like receptor family (Table 1) in our study is consistent with a recent finding that the cross-talk between Nod1/Nod2 receptors and type 1 IFNs induced during a viral infection, promoted lethality in mice superinfected with $E$. coli [45]. Upregulation of genes encoding a matrix metalloproteinase, MMP14 and also caspase 10 may provide a mechanism by which the viruses induce lysis of the host cell components and, in the process, facilitate increased adherence and possibly invasion of bacteria.

\section{Conclusions}

In summary, we have shown that: (a) D562 cells were permissive to RSV and HPIV3; (b) these viruses augmented the adherence of $S$. pneumoniae to the host cells by a factor of 1.3-2.0; (c) infection with both RSV and HPIV3 enhanced the transcription of host cell adhesion molecules that facilitate or mediate bacterial adhesion in general; and (d) there is a core transcriptome (at least in the TIGR4 strain) that represents the basic machinery required for adherence of pneumococci to D562 cells regardless of whether the cell is infected with a virus or not. Further elucidation of these mechanisms is most likely to be obtained by specific inhibition of the expression of the host cell receptors or by bacterial gene knockout experiments.

\section{Additional file}

Additional file 1: Table S1. is a table listing the primers used for qRTPCR analysis of human genes. Table $\mathbf{S 2}$. is a table listing the primers used for GRT-PCR analysis of pneumococcal genes. Table S3. is a table listing genes commonly significantly regulated by TIGR4 in contact with either viral- or mock-infected human pharyngeal cells. Figure S1. is a figure depicting the correlation of the $\log _{2}$ ratios of TIGR4 adherent to mock-infected cells and to HIPV3-infected cells. Figure S2. is a figure showing graphs of qRT-PCR validation of human and pneumococcal microarray results.

\section{Abbreviations}

CEACAM: Carcinoembryonic antigen-related cell adhesion molecule; CPE: Cytopathic effect; D562 cells: Detroit 562 cells; FN: Fibronectin; HCL: Hierarchical clustering; HPIV3: Human parainfluenza virus 3; ISGs: Interferon-stimulated genes; MARCO: Macrophage receptor; NA: Neuraminidase; PAFR: Platelet-activating factor; RSV: Respiratory syncytial virus; SAM: Significance analysis of microarrays.

\section{Competing interests}

JAGS reports receiving a grant from GlaxoSmithKline Biologicals (Anthony Scott, Kayla Laserson; $\$ 2,575,975$; Oct 2010-Sep 2013) for a study entitled: 'A phase IV multi-site observational epidemiology study to assess potential risk for adverse events following immunization that may be associated with misuse of a two-dose vial of 10-valent Pneumococcal Conjugate Vaccine (Synflorix) in Kenya'.

\section{Authors' contributions}

SZKM carried out the adherence assays and pneumococcal microarray experiments, analyzed the data and drafted the manuscript. TCTP participated in the design and performance of viral adherence assays. NK performed the human microarray experiments and qRT-PCR experiments. SRS participated in the design and performance of bacterial adherence assays and RNA extractions and drafting of the manuscript. JCDH participated in the design and analysis of all experiments involving molecular work in this manuscript. NI participated in the pneumococcal microarray experiments. VGH performed qRT-PCR experiments. DRR participated in the bioinformatics analysis of microarray work. DDE, GMC, JS participated in the design of the study. JAGS and HT conceived the study, participated in the study design and development, analysis and drafting of the manuscript. All authors read and approved this manuscript.

\section{Acknowledgements}

This work was supported by grants from the Wellcome Trust to Prof. Anthony Scott (081835) and University of Maryland internal funds to Dr. Hervé Tettelin. The authors wish to thank Dr. Norman Lee (George Washington University, Washington DC, USA) and the Pathogen Functional Genomics Resource Center (PFGRC) at the J. Craig Venter Institute (JCVI, Rockville, MD, USA) for providing microarray slides, Gowrisankar Rajam (Centers for Disease Control and Prevention, CDC, Atlanta, GA, USA) for technical assistance and Margaret Mackinnon and Greg Fegan (KEMRI/Wellcome Trust, Kilifi, Kenya) for expert advice on statistical methods.

\section{Author details}

${ }^{1}$ Kenya Medical Research Institute - Wellcome Trust Research Programme, Kilifi, Kenya. ${ }^{2}$ Department of Microbiology and Immunology, Institute for Genome Sciences, University of Maryland School of Medicine, Baltimore, MD, USA. ${ }^{3}$ Division of Viral Diseases, Centers for Disease Control and Prevention, Atlanta, GA, USA. ${ }^{4}$ Division of Bacterial Diseases, Centers for Disease Control and Prevention, Atlanta, GA, USA. ${ }^{5}$ Nuffield Department of Clinical Medicine, University of Oxford, Oxford, UK. ${ }^{6}$ Present address: Respiratory \& Meningeal Pathogens Research Unit, University of the Witwatersrand/Medical Research Council, Johannesburg, South Africa.

Received: 10 October 2012 Accepted: 24 May 2013

Published: 7 June 2013

\section{References}

1. Plotkowski MC, Puchelle E, Beck G, Jacquot J, Hannoun C: Adherence of type I Streptococcus pneumoniae to tracheal epithelium of mice infected with influenza A/PR8 virus. Am Rev Respir Dis 1986, 134:1040-1044.

2. McCullers JA: Insights into the interaction between influenza virus and pneumococcus. Clin Microbiol Rev 2006, 19:571-582.

3. Brundage JF: Interactions between influenza and bacterial respiratory pathogens: implications for pandemic preparedness. Lancet Infect Dis 2006, 6:303-312

4. Memoli MJ, Morens DM, Taubenberger JK: Pandemic and seasonal influenza: therapeutic challenges. Drug Discov Today 2008, 13:590-595. 
5. Morens DM, Taubenberger JK, Fauci AS: Predominant role of bacterial pneumonia as a cause of death in pandemic influenza: implications for pandemic influenza preparedness. J Infect Dis 2008, 198:962-970.

6. Diavatopoulos DA, Short KR, Price JT, Wilksch JJ, Brown LE, Briles DE, Strugnell RA, Wijburg OL: Influenza A virus facilitates Streptococcus pneumoniae transmission and disease. FASEB J 2010, 24:1789-1798.

7. McCullers JA: Preventing and treating secondary bacterial infections with antiviral agents. Antivir Ther 2011, 16:123-135.

8. McCullers JA, McAuley JL, Browall S, Iverson AR, Boyd KL, Henriques Normark B: Influenza enhances susceptibility to natural acquisition of and disease due to Streptococcus pneumoniae in ferrets. $J$ Infect Dis 2010, 202:1287-1295.

9. Seki M, Kosai K, Hara A, Imamura Y, Nakamura S, Kurihara S, Izumikawa K, Kakeya $\mathrm{H}$, Yamamoto $Y$, Yanagihara $\mathrm{K}$, et al: Expression and DNA microarray analysis of a platelet activating factor-related molecule in severe pneumonia in mice due to influenza virus and bacterial co-infection. Jpn $J$ Infect Dis 2009, 62:6-10.

10. Wang Q, Nagarkar DR, Bowman ER, Schneider D, Gosangi B, Lei J, Zhao Y, McHenry CL, Burgens RV, Miller DJ, et al: Role of double-stranded RNA pattern recognition receptors in rhinovirus-induced airway epithelial cell responses. J Immunol 2009, 183:6989-6997.

11. Hament JM, Kimpen $J$, Fleer A, Wolfs TF: Respiratory viral infection predisposing for bacterial disease: a concise review. FEMS Immunol Med Microbiol 1999, 26:189-195.

12. Kash JC, Walters KA, Davis AS, Sandouk A, Schwartzman LM, Jagger BW, Chertow DS, Li Q, Kuestner RE, Ozinsky A, et al: Lethal Synergism of 2009 Pandemic H1N1 Influenza Virus and Streptococcus pneumoniae Coinfection Is Associated with Loss of Murine Lung Repair Responses. MBio 2011, 2:e00172-11.

13. McNamee LA, Harmsen AG: Both influenza-induced neutrophil dysfunction and neutrophil-independent mechanisms contribute to increased susceptibility to a secondary Streptococcus pneumoniae infection. Infect Immun 2006, 74:6707-6721.

14. Sun K, Metzger DW: Inhibition of pulmonary antibacterial defense by interferon-gamma during recovery from influenza infection. Nat Med 2008, 14:558-564.

15. Jamieson AM, Yu S, Annicelli CH, Medzhitov R: Influenza virus-induced glucocorticoids compromise innate host defense against a secondary bacterial infection. Cell Host Microbe 2010, 7:103-114.

16. Navarini AA, Recher M, Lang KS, Georgiev P, Meury S, Bergthaler A, Flatz L, Bille J, Landmann R, Odermatt B, et al: Increased susceptibility to bacterial superinfection as a consequence of innate antiviral responses. Proc Nat Acad Sci U S A 2006, 103:15535-15539.

17. Small CL, Shaler CR, McCormick S, Jeyanathan M, Damjanovic D, Brown EG, Arck P, Jordana M, Kaushic C, Ashkar AA, et al: Influenza infection leads to increased susceptibility to subsequent bacterial superinfection by impairing NK cell responses in the lung. J Immunol 2010, 184:2048-2056.

18. Raza MW, El Ahmer OR, Ogilvie MM, Blackwell CC, Saadi AT, Elton RA, Weir DM: Infection with respiratory syncytial virus enhances expression of native receptors for non-pilate Neisseria meningitidis on HEp-2 cells. FEMS Immunol Med Microbiol 1999, 23:115-124.

19. Hakansson A, Kidd A, Wadell G, Sabharwal H, Svanborg C: Adenovirus infection enhances in vitro adherence of Streptococcus pneumoniae. Infect Immun 1994, 62:2707-2714.

20. Tong HH, Long JP, Li D, DeMaria TF: Alteration of gene expression in human middle ear epithelial cells induced by influenza A virus and its implication for the pathogenesis of otitis media. Microb Pathog 2004, 37:193-204.

21. Wang $\mathrm{JH}$, Kwon $\mathrm{HJ}$, Jang $\mathrm{YJ}$ : Rhinovirus enhances various bacterial adhesions to nasal epithelial cells simultaneously. Laryngoscope 2009, 119:1406-1411.

22. King QO, Lei B, Harmsen AG: Pneumococcal surface protein A contributes to secondary Streptococcus pneumoniae infection after influenza virus infection. J Infect Dis 2009, 200:537-545.

23. Rameix-Welti MA, Zarantonelli ML, Giorgini D, Ruckly C, Marasescu M, van der Werf S, Alonso JM, Naffakh N, Taha MK: Influenza A virus neuraminidase enhances meningococcal adhesion to epithelial cells through interaction with sialic acid-containing meningococcal capsules. Infect Immun 2009, 77:3588-3595.

24. Hament JM, Aerts PC, Fleer A, van Dijk H, Harmsen T, Kimpen $J$, Wolfs TF: Direct binding of respiratory syncytial virus to pneumococci: a phenomenon that enhances both pneumococcal adherence to human epithelial cells and pneumococcal invasiveness in a murine model. Pediatr Res 2005, 58:1198-1203.

25. Sampson JS, O'Connor SP, Stinson AR, Tharpe JA, Russell H: Cloning and nucleotide sequence analysis of psaA, the Streptococcus pneumoniae gene encoding a 37-kilodalton protein homologous to previously reported Streptococcus sp. adhesins. Infect Immun 1994, 62:319-324.

26. Romero-Steiner S, Pilishvili T, Sampson JS, Johnson SE, Stinson A, Carlone GM, Ades EW: Inhibition of pneumococcal adherence to human nasopharyngeal epithelial cells by anti-PsaA antibodies. Clin Diagn Lab Immunol 2003 10:246-251.

27. Barocchi MA, Ries J, Zogaj X, Hemsley C, Albiger B, Kanth A, Dahlberg S, Fernebro J, Moschioni M, Masignani V, et al: A pneumococcal pilus influences virulence and host inflammatory responses. Proc Natl Acad Sci U S A 2006, 103:2857-2862

28. Aaberge IS, Eng J, Lermark G, Lovik M: Virulence of Streptococcus pneumoniae in mice: a standardized method for preparation and frozen storage of the experimental bacterial inoculum. Microb Pathog 1995 18:141-152.

29. Marchese A, Debbia EA, Arvigo A, Pesce A, Schito GC: Susceptibility of Streptococcus pneumoniae strains isolated in Italy to penicillin and ten other antibiotics. J Antimicrob Chemother 1995, 36:833-837.

30. Jiang SM, Ishmael N, Dunning Hotopp J, Puliti M, Tissi L, Kumar N, Cieslewicz MJ, Tettelin H, Wessels MR: Variation in the group B Streptococcus CsrRS regulon and effects on pathogenicity. J Bacteriol 2008, 190:1956-1965.

31. Saeed Al, Sharov V, White J, Li J, Liang W, Bhagabati N, Braisted J, Klapa M, Currier T, Thiagarajan M, et al: TM4: a free, open-source system for microarray data management and analysis. Biotechniques 2003, 34:374-378.

32. Livak KJ, Schmittgen TD: Analysis of relative gene expression data using real-time quantitative PCR and the 2(-Delta Delta $C(T)$ ) Method. Methods 2001, 25:402-408.

33. Selinger DS, Reed WP: Pneumococcal adherence to human epithelial cells. Infect Immun 1979, 23:545-548.

34. Avadhanula V, Rodriguez CA, Devincenzo JP, Wang Y, Webby RJ, Ulett GC, Adderson EE: Respiratory viruses augment the adhesion of bacterial pathogens to respiratory epithelium in a viral species- and cell typedependent manner. J Virol 2006, 80:1629-1636.

35. Avadhanula V, Wang Y, Portner A, Adderson E: Nontypeable Haemophilus influenzae and Streptococcus pneumoniae bind respiratory syncytial virus glycoprotein. J Med Microbiol 2007, 56:1133-1137.

36. Techasaensiri B, Techasaensiri C, Mejias A, McCracken GH Jr, Ramilo O: Viral coinfections in children with invasive pneumococcal disease. Pediatr Infect Dis J 2010, 29:519-523.

37. Hammitt LL, Kazungu S, Morpeth SC, Gibson DG, Mvera B, Brent AJ, Mwarumba S, Onyango CO, Bett A, Akech DO, et al: A preliminary study of pneumonia etiology among hospitalized children in Kenya. Clinical infectious diseases : an official publication of the Infectious Diseases Society of America 2012, 54(Suppl 2):S190-S199.

38. Peltola VT, McCullers JA: Respiratory viruses predisposing to bacterial infections: role of neuraminidase. Pediatr Infect Dis J 2004, 23:S87-S97.

39. Kirdis E, Jonsson IM, Kubica M, Potempa J, Josefsson E, Masalha M, Foster SJ, Tarkowski A: Ribonucleotide reductase class III, an essential enzyme for the anaerobic growth of Staphylococcus aureus, is a virulence determinant in septic arthritis. Microb Pathog 2007, 43:179-188.

40. Bortoni ME, Terra VS, Hinds J, Andrew PW, Yesilkaya H: The pneumococcal response to oxidative stress includes a role for Rgg. Microbiology 2009, 155:4123-4134.

41. Orihuela CJ, Radin JN, Sublett JE, Gao G, Kaushal D, Tuomanen El: Microarray analysis of pneumococcal gene expression during invasive disease. Infect Immun 2004, 72:5582-5596.

42. Tamura GS, Nittayajarn A, Schoentag DL: A glutamine transport gene, $\mathrm{g} \ln \mathrm{Q}$, is required for fibronectin adherence and virulence of group $B$ streptococci. Infect Immun 2002, 70:2877-2885.

43. Wang J, Gray-Owen SD, Knorre A, Meyer TF, Dehio C: Opa binding to cellular CD66 receptors mediates the transcellular traversal of Neisseria gonorrhoeae across polarized T84 epithelial cell monolayers. Mol Microbiol 1998, 30:657-671.

44. Mittal R, Gonzalez-Gomez I, Prasadarao NV: Escherichia coli K1 promotes the ligation of CD47 with thrombospondin-1 to prevent the maturation 
of dendritic cells in the pathogenesis of neonatal meningitis. J Immunol 2010, 185:2998-3006.

45. Kim YG, Park JH, Reimer T, Baker DP, Kawai T, Kumar H, Akira S, Wobus C, Nunez G: Viral infection augments Nod $1 / 2$ signaling to potentiate lethality associated with secondary bacterial infections. Cell Host Microbe 2011, 9:496-507.

doi:10.1186/1471-2164-14-378

Cite this article as: Kimaro Mlacha et al:: Transcriptional adaptation of pneumococci and human pharyngeal cells in the presence of a virus infection. BMC Genomics 2013 14:378.

\section{Submit your next manuscript to BioMed Central and take full advantage of:}

- Convenient online submission

- Thorough peer review

- No space constraints or color figure charges

- Immediate publication on acceptance

- Inclusion in PubMed, CAS, Scopus and Google Scholar

- Research which is freely available for redistribution 